\title{
Interdisciplinarity in Nursing education and research
}

\section{Maria Amélia de Campos Oliveira ${ }^{1}$}

When the subject under discussion is interdisciplinarity, other themes emerge such as multidisciplinarity, crossdisciplinarity, and others. These terms share the same root word: discipline, which from the Latin discere means to learn, which is also the origin of the word disciple.

Discipline can be defined as a systematically organized group of knowledge regarding an object, epistemic field or part of a curriculum. It is a way to structure and organize the knowledge about certain objects using a unique methodology.

Considering interdisciplinarity from the curricular perspective (i.e., of teaching and learning) presupposes the integration between the disciplines comprising the curriculum in several educational areas. From the epistemic or knowledge perspective, it refers to how the integrated meaning of an object, event or situation is created, as a response to its complexity.

Multidisciplinarity differs from interdisciplinarity in regards to the level of mutual interaction assumed by the different disciplines involved. In multidisciplinarity, the disciplines work together while preserving their independence; in other words, the limits of the disciplines are preserved. In interdisciplinarity, there is a strong interdependence and each discipline uses a similar or the same approach of the others, becoming mutually permeated.

Crossdisciplinarity, on the other hand, is more of an image-objective, a horizon that points to another form of knowledge besides the logical-rational, which we so often tend to value. It also involves the dimensions of subjectivity and intuition, commonly discarded by scientific thinking.

It must be underlined that interdisciplinarity cannot be separated from disciplinarity, because it requires competent disciplinary knowledge. However, each expert must recognize the partial and relative character of their own discipline and the focus it adopts.

What are the requirements for interdisciplinarity? Sensitivity to complexity, the ability to seek common ground among different fields of knowledge, attention to deep structures capable of connecting things that are apparently unconnectable, an attitude of being curious and keeping an open mind, a taste for collaboration and group work, and the courage to leave the specific field of knowledge to adventure in other epistemic fields are the necessary ingredients that allow interdisciplinarity to flourish.

What are the obstacles to interdisciplinarity? There are epistemological obstacles, because the dominant science paradigm implies that every other form is considered less scientific or valid, institutional obstacles, because whenever we propose another form of teaching and/or doing research we run into the inertia and the resistance of institutions; psychosociological obstacles, resulting from the difficulty that we experience in opening ourselves to new ways of understanding subjects/objects, and cultural obstacles, resulting from the hegemonic way of creating science.

What are the limits to the practice of interdisciplinarity? One of them is our limited knowledge regarding other areas, in the way that any incursion into other fields demands considerable effort. Another difficulty originates in interdisciplinary problems. The problems are complex and our view determines how we solve them in a way that is unique to our discipline.

In the health care process, a reality that we deal with every day, is teamwork a possibility for creating interdisciplinarity? That will depend on the degree of cooperation and communication between teams.

In undergraduate education, some current curricula are examples of how the interdisciplinary perspective is being adopted- the so-called 'integrated curricula'. The best known are those of Faculdade de Medicina de Marilia (FAMEMA) and Universidade de Londrina (UEL). At the University of São Paulo School of Nursing-Escola de Enfermagem da Universidade de São Paulo (EEUSP), we are making our own attempt and are now in the third year of a new curricular proposal that aims at integrating disciplinary studies.

\footnotetext{
${ }^{1}$ Full Professor. Head of the Collective Health Nursing Department, School of Nursing, University of São Paulo. Leader of the Research Group Avaliação de Necessidades de Saúde - CNPq (Health Needs Assessment). São Paulo, SP, Brazil. macampos@usp.br
} 
The Health Ministry itself has been using several strategies that promote interprofessional education, the new designation that is being adopted to assign an interdisciplinary perspective in education. The PET-Saúde, Pró-Saúde and Pró-Ensino na Saúde programs are particularly successful initiatives of the Health Ministry.

In graduate studies, the advancements are a bit more significant because research calls for interdisciplinarity, requiring contributions from several disciplines. In the case of nursing research, the mere complexity of the subjects that we deal with, such as violence, poverty, and vulnerability require a more interdisciplinary approach. In the CAPES (Coordination for the Improvement of Higher Education Personnel), the interdisciplinary area created in 1999 today contains more than three hundred courses that are referred to as being interdisciplinary, which imply a series of challenges and obstacles to be overcome.

The National Academy of Sciences defines interdisciplinary research as the method of doing research by groups or individuals, integrating data, techniques, instruments, perspectives, concepts and/or theories of two or more disciplines to improve understanding or solve problems whose solutions surpass the domains of a single discipline or area of knowledge.

The disintegration of knowledge and the consequent isolation keeps scientists alienated from the more general process of developing knowledge and its relationship with the world. We find it difficult to go beyond our own discursive principles, our language used to create science, the theoretical perspectives and the modes of operation in which we were trained. This is because creating science presupposes a training that, to some extent, will determine what and how we will practice as researchers and professors throughout our entire professional life.

The author ${ }^{(1)}$ of La rebelión de las masas summarizes the danger of isolation:

Before, men could be easily separated into ignorant and wise, more or less wise and more or less ignorant. But experts cannot be subsumed into either of these categories. They are not wise, because they formally ignore everything that does not fit their expertise; but they are not ignorant either, because they are 'men of science' and they know very well their minimal part in the universe. We must say that they are 'wise-ignorant' individuals, something extremely serious, because it refers to a person who behaves towards every issue they consider irrelevant not as an ignorant, but with all the petulance of whom, in their own expertise, is wise.

\section{Reference}

1. Ortega y Gasset, J. A rebelião das massas. São Paulo: Relógio D’Agua; 1998. 